\title{
Impact of ovarian function on cardiovascular health in women: focus on hypertension
}

\author{
This article was published in the following Dove Press journal: \\ International Journal of Women's Health \\ 24 January 2014 \\ Number of times this article has been viewed
}

\author{
Christine Maric-Bilkan' \\ Emily L Gilbert ${ }^{2}$ \\ Michael J Ryan ${ }^{2}$ \\ 'Division of Cardiovascular Sciences, \\ National Heart, Lung and Blood \\ Institute, Bethesda, MD, ${ }^{2}$ Department \\ of Physiology and Biophysics, \\ University of Mississippi Medical \\ Center, Jackson, MS, USA
}

\begin{abstract}
Arterial blood pressure levels and the prevalence of hypertension are generally lower in premenopausal women compared with age-matched men. The lower blood pressure levels in premenopausal women are associated with a lower risk of the development and progression of cardiovascular disease. In contrast, menopause, a state characterized by a physiologic reduction in ovarian hormone levels, is associated with progressive increases in blood pressure and an overall increase in the risk of cardiovascular disease. These observations suggest an association between blood pressure regulation and changes in ovarian hormone levels, estrogens in particular. In addition to menopause, the risk of hypertension and cardiovascular disease is also dramatically increased in premenopausal women with chronic diseases such as diabetes and systemic lupus erythematosus. Studies suggest that these chronic diseases may be associated with an imbalance in ovarian hormones, which may explain the increased risk of hypertension and cardiovascular disease in these women. However, the use of hormone therapy to manage the risk and prevent the development of hypertension and cardiovascular diseases in women remains controversial. The precise mechanisms by which estrogens contribute to the regulation of blood pressure are still not completely understood. However, accumulating evidence suggests that modulating the activity of locally active hormone systems is one of the major mechanisms by which estrogens exert their effects on target organs, including the vasculature, kidneys, and immune system. In particular, the interaction between estrogens and the renin-angiotensin system has been implicated in the regulation of blood pressure and cardiovascular function in both humans and experimental models. This review summarizes our current understanding of the mechanisms by which estrogens regulate blood pressure and the potential use of hormone therapy in prevention of hypertension and consequent cardiovascular risk.
\end{abstract}

Keywords: blood pressure, ovarian hormones, menopause, cardiovascular risk

\section{Sex differences in blood pressure}

Numerous studies have shown that while both systolic and diastolic blood pressure rise with advancing age, blood pressure levels are generally lower in women compared with aged-matched men across most of their lifespan..$^{1-3}$ Interestingly though, the two age periods where this clear sexual dimorphism favoring women is not observed are prepuberty and menopause, suggesting a potential role of ovarian hormones. Analysis of data from the National Health and Nutrition Examination Survey (NHANES), which included 16,563 persons between the ages of 6 months and 74 years, showed no sex differences in blood pressure levels before the age of 12 years. ${ }^{4}$ These data are comparable with those from the NHANES II analysis and a meta-analysis of several large national surveys in the UK that showed no sex differences in blood pressure levels between
Correspondence: Christine Maric-Bilkan Division of Cardiovascular Sciences, Vascular Biology and Hypertension Branch, NIH/NHLBI, Two Rockledge Center, Room 8I I0, 670I Rockledge Drive, Bethesda, MD 20892-7940, USA $\mathrm{Tel}+\mathrm{I} 30 \mathrm{I} 4350486$

Fax + I 30I 4802858

Email christine.maric-bilkan@nih.gov 
boys and girls before puberty. ${ }^{5,6}$ Following puberty and up until menopause, women have lower blood pressure levels compared with aged-matched men, which is an observation that led many to believe in the "female advantage", or the protective effect of estrogens with respect to blood pressure regulation. ${ }^{7-9}$ The concept of the protective effects of estrogen are further supported by the fact that, around the time of menopause, blood pressure levels start rising in women, reaching levels comparable with those in men. ${ }^{10,11}$ Since both the prepubertal and menopausal periods are characterized by low levels of estrogens, it is conceivable that the loss of the "female advantage" with respect to blood pressure may be consequent to the loss of estrogens. Many studies have actually tested the hypothesis that estrogens reduce blood pressure in both humans and experimental models of hypertension, and this review will focus on summarizing some of the findings of these studies.

Although estrogen is the predominant ovarian hormone studied in the context of cardiovascular disease and hypertension in women, it is important to stress that other hormones, such as progesterone, may also play an important role. While it is generally believed that progestins oppose the cardioprotective effects of estrogens (eg, progesterone induces vasoconstriction of estrogen-induced vasodilation ${ }^{12}$ ), this is not a universal finding. Some studies have shown that, depending on the formulation, progestins may in fact enhance the positive vascular effects of estrogens. ${ }^{13}$ However, most clinical trials, such as the Heart and Estrogen/progestin Replacement Study (HERS), HERS-II, and the Women's Health Initiative (WHI) do not support the experimental findings and demonstrate adverse cardiovascular events from combined hormone therapy (discussed later in this review). ${ }^{14,15}$ While the outcomes of these studies may be affected by the timing and different formulations of hormones used, as well as the study population, clearly additional studies are needed to fully understand the contribution of progestins to cardiovascular function in women.

While the generally lower blood pressure levels in women may be attributable to the blood pressure-lowering effects of estrogens, it may also be argued that the higher blood pressure levels observed in men may be due to the presence of testosterone. Indeed, numerous experimental studies have shown that castration, and thus removal of endogenous testosterone, lowers blood pressure, while testosterone replacement in castrated rats increases blood pressure. ${ }^{16-18}$ Somewhat paradoxically, hypertensive men actually show lower testosterone levels, ${ }^{19}$ suggesting that it may not be the actual levels but rather the activity of testosterone that may be altered in hypertension. Further supporting the potential contribution of testosterone to the development of hypertension is the fact that women with polycystic ovary syndrome, which is characterized by elevated blood pressure, have increased testosterone levels. ${ }^{20}$

\section{Sex differences in hypertension}

Premenopausal women not only have lower blood pressure levels compared with men, but they also have a lower prevalence of hypertension. Analysis of the data from NHANES conducted in 1988-1994 and 1999-2004 surveying the US adult population aged $\geq 18$ years showed that women, regardless of race and ethnicity, had a lower prevalence of hypertension compared with men across all age groups. ${ }^{21}$ Similarly, the Hypertension Detection and Follow-up Program Cooperative Group screened 158,906 persons and found that hypertension was less prevalent in women than in men. ${ }^{22}$ Interestingly, with regard to recent reports on heart disease and stroke statistics, the 2011 and 2013 update from the American Heart Association reported that the prevalence of hypertension is now nearly equal between men and women. ${ }^{22,23}$ These observations suggest that either the incidence of hypertension in women may be on the rise or that better hypertension control is achieved in males than in females. However, it is important to note that this American Heart Association report does not indicate the age group in which the analysis was performed, and it is possible that both premenopausal and postmenopausal women were grouped together. This becomes an important issue given that the prevalence of hypertension in postmenopausal women not only increases in comparison with premenopausal women, but exceeds that in age-matched men. The findings of SIMONA (the Study on Hypertension Prevalence in Menopause in the Italian population), a large cross-sectional study including 18,326 women aged 46-59 years, showed that menopause is associated with higher blood pressure, even after adjustment for age and body mass index. ${ }^{23}$ In the US, over $75 \%$ of women $\geq 60$ years of age are hypertensive, and a significant percentage of this is due to the development of salt sensitivity. ${ }^{10,24}$ Analyses of the NHANES III and IV studies showed that the prevalence of hypertension in women $\geq 60$ years of age was greater compared with agematched men, regardless of ethnicity. ${ }^{25}$ Cumulatively, these data support the concept that loss of ovarian hormones, as occurs in menopause, is associated with loss of the "female advantage" with respect to blood pressure. It should be pointed out that menopause is not only associated with loss of ovarian hormones but also with biological aging, so the increase in prevalence of hypertension following menopause may be 
merely due to advancing age. However, studies conducted in premenopausal women who have undergone surgical menopause showed that hysterectomy was associated with hypertension $^{25}$ and that the prevalence of salt sensitivity doubles as early as 4 months after surgical menopause, thus significantly increasing the risk of developing hypertension. ${ }^{26}$ These observations underscore the importance of ovarian hormones in blood pressure regulation.

\section{Estrogens and risk of hypertension in chronic diseases}

In addition to natural and surgical menopause, chronic diseases such as diabetes, obesity, and inflammatory disorders are also associated with a loss or imbalance in ovarian hormone levels and, consequently, an increased risk of hypertension. Studies have shown that both type 1 and type 2 diabetes are characterized by decreased circulating estrogen levels, ${ }^{27-29}$ which may explain why these women have a higher prevalence of hypertension and associated cardiovascular disease compared with nondiabetic women..$^{30,31}$ It is noteworthy that reduction in estrogen levels, at least in type 1 diabetic women, is observed in premenopausal women, suggesting that the decline in estrogen levels is not age-related. In addition to reduced estrogen levels, women with type 2 diabetes also show elevated androgen levels ${ }^{27,32}$ which on its own may increase the risk of hypertension and cardiovascular disease. However, it is most likely that the relative balance between estrogens and androgens, rather than the absolute circulating levels of a hormone, contributes to the overall risk of disease development.

\section{Hypertension and risk of cardiovascular disease in women}

While we think of hypertension and cardiovascular disease as primarily affecting men, cardiovascular disease is the single leading cause of death for women over 25 years of age worldwide. ${ }^{33,34}$ Furthermore, the prevalence of cardiovascular disease around the world is projected to continue to increase, primarily due to adverse lifestyle choices and the increasing life expectancy, especially among women. ${ }^{35}$ Despite the fact that deaths from cardiovascular disease have been gradually declining since the 1980s for men, deaths from cardiovascular disease continue to increase among women, ${ }^{36}$ for reasons that remain unclear and understudied. A plausible explanation for the high death rates in women may be that cardiovascular disease is often misdiagnosed due to the fact that women experience the symptoms of the disease differently to men. In addition, many basic and clinical studies have shown that the mechanisms underlying cardiovascular disease differ between the sexes (reviewed by Regitz-Zagrosek et $\mathrm{al}^{37}$ ), suggesting that treatment for cardiovascular disease should be sex-specific. However, women generally continue to receive the same treatment for cardiovascular disease as men, which may potentially explain why these same treatments may not be as effective in women and why women experience poorer outcomes, including death following a cardiovascular event. The lack of sex-specific treatments will also continue to be an issue unless women are equally represented in cardiovascular prevention clinical trials. At present, the mean percentage of women included in these trials is $30 \%$ and only about a third of all reports from these trials report their data in a sex-specific manner. ${ }^{38}$ Thus, inclusion of a greater number of women in clinical trials identifying sex-specific risk factors and continued investigation into the mechanisms underlying sex differences in cardiovascular function and disease is needed to reduce death from cardiovascular disease in both women and men.

Risk factors for cardiovascular disease in both women and men include hypertension, dyslipidemia, smoking, diabetes, obesity, and limited physical activity, with hypertension being the most significant. ${ }^{39}$ Unlike in men, cardiovascular disease rarely develops in women without at least one of these risk factors. ${ }^{40}$ Hypertension is the most common risk factor for cardiovascular disease in women. Several studies have shown a direct correlation between higher levels of both systolic and diastolic blood pressure and risk of cardiovascular disease. ${ }^{41,42}$ Specifically, for every increase of $20 \mathrm{mmHg}$ systolic or $10 \mathrm{mmHg}$ diastolic blood pressure, there is a doubling in mortality from cardiovascular disease in both men and women between the ages of 40 and 89 years. Interestingly, some studies have found that higher blood pressure has a greater impact on cardiovascular mortality in women compared with men, ${ }^{43,44}$ suggesting that reduction in prevalence of hypertension in women may significantly reduce the prevalence of cardiovascular disease.

It is also important to recognize that while estrogens are often considered to protect against cardiovascular risk factors, including hypertension, there are clinical conditions in which estrogens are thought to have a pathogenic role and may also increase cardiovascular risk. One such example is systemic lupus erythematosus (SLE), a chronic autoimmune disorder that predominantly affects women of reproductive age. The disease is characterized by activation of the humoral immune system to promote antibodies against host tissues. Interestingly, women with SLE have a markedly increased prevalence of hypertension and cardiovascular disease, which is the major cause of mortality in these patients. ${ }^{45-47}$ 
The strong predilection for women of reproductive age has led to the commonly held belief that estrogens promote this chronic disease and suggests the possibility that estrogens could increase the risk of hypertension and cardiovascular disease (discussed below). Therefore, diseases like SLE highlight the potential complexity of the pathways by which estrogens regulate the cardiovascular system.

\section{Effects of estrogens on blood pressure regulation}

While we most commonly think of estrogen as a hormone important in the reproductive system, accumulating evidence suggests that estrogen plays an important role in regulating other biological functions, including blood pressure. Several hormonal and organ systems contribute to the regulation of blood pressure, including, but not limited to, the vasculature, kidney, and immune system. Interestingly, these are also target organs/systems for estrogen, suggesting that the effects of estrogen on these organs may be important in blood pressure control. Abnormal regulation of these interactions may contribute to the development of hypertension and subsequent cardiovascular disease. We provide a brief summary of the effects of estrogens related to blood pressure control in the vasculature, kidney, and immune system.

\section{Effects of estrogen on the vasculature}

Estrogens regulate vascular function by modulation of a variety of biological cascades, including the renin-angiotensin system and endothelin and reducing oxidative stress. In cultured vascular smooth muscle cells, 17 $\beta$-estradiol downregulates expression of angiotensin $\mathrm{AT}_{1}$ receptor mRNA, while ovariectomized rats have increased expression of angiotensin $\mathrm{AT}_{1}$ receptor mRNA in the aorta, which is reversed by repletion of $17 \beta$-estradiol. ${ }^{48}$ Replacement of $17 \beta$-estradiol in ovariectomized rats also reduces plasma angiotensinconverting enzyme activity as well as circulating levels of angiotensin II. ${ }^{49}$ This $17 \beta$-estradiol-mediated reduction in expression of angiotensin $\mathrm{AT}_{1}$ receptor and angiotensinconverting enzyme activity may be a mechanism by which $17 \beta$-estradiol prevents some of the vasoconstrictor effects of the renin-angiotensin system in the vasculature. Estrogens also afford cardiovascular protection because of their ability to modulate levels and activity of endothelin, a potent vasoconstrictor. The biological function of endothelin is mediated via $\mathrm{ET}_{\mathrm{A}}$ and $\mathrm{ET}_{\mathrm{B}}$ receptors, with $\mathrm{ET}_{\mathrm{A}}$ receptors primarily leading to the vasoconstrictor effects of endothelin and activation of $\mathrm{ET}_{\mathrm{B}}$ receptors promoting vasodilation. The ratio of $\mathrm{ET}_{\mathrm{A}}$ to $\mathrm{ET}_{\mathrm{B}}$ receptors in premenopausal women favors the vasodilatory effects of endothelin via $\mathrm{ET}_{\mathrm{B}}$ receptors. ${ }^{50}$ High levels of estrogens are associated with reduced levels of endothelin, ${ }^{51}$ and hormone therapy in postmenopausal women reduces plasma levels of endothelin. ${ }^{52}$ In addition, animal studies suggest that $17 \beta$-estradiol inhibits the synthesis of endothelin and attenuates endothelial dysfunction. ${ }^{53}$

Several studies have shown that estrogens protect the vasculature via their antioxidant activity. Specifically, 17ßestradiol induces activation of superoxide dismutase, an enzyme responsible for removal of superoxide. ${ }^{54}$ Superoxide is a major contributor to oxidative stress and can bind nitric oxide, limiting its ability to cause vasodilation. In animal studies, $17 \beta$-estradiol contributes to reduced endothelial dysfunction in female spontaneously hypertensive rats by modulating the activity of nicotinamide adenine dinucleotide phosphate oxidase, an intracellular source of superoxide. ${ }^{55}$

\section{Effects of estrogen on the kidney}

The kidney plays a major role in long-term regulation of blood pressure, ${ }^{56}$ so maintaining normal renal function is imperative for maintaining normal blood pressure. It is well documented that premenopausal women have a far lower prevalence of renal disease compared with age-matched men, but this relationship no longer exists following menopause. ${ }^{57,58}$ These observations suggest a positive correlation between estrogen levels and renal function. Indeed, several experimental studies have shown that removal of endogenous estrogen accelerates the development and progression of renal disease..$^{59,60}$ In some experimental models, removal of endogenous estrogen also increases blood pressure, which may further contribute to worsening renal function. ${ }^{61,62}$ Treatment with $17 \beta$-estradiol has been shown to attenuate glomerulosclerosis and tubulointerstitial fibrosis, which are hallmarks of progressive renal disease, via reducing collagen type I and type IV synthesis, decreasing expression of transforming growth factor-beta protein, increasing expression of matrix metalloproteinases, and inhibiting apoptosis. ${ }^{60,63,64} 17 \beta$-estradiol has been shown to regulate the expression and activity of locally active vasoactive systems, including the renin-angiotensin and endothelin systems, both of which stimulate abnormal cell growth and metabolism in the extracellular matrix, and contribute to the vascular dysfunction associated with renal disease. ${ }^{65,66}$ Given that the renin-angiotensin system plays a crucial role in the control of blood pressure by regulating its activity, $17 \beta$-estradiol may play an important role in blood pressure control. In addition, $17 \beta$-estradiol acts as a vasodilator by increasing expression of nitric oxide synthase activity and increasing production of nitric oxide. ${ }^{67}$ 


\section{Effects of estrogen \\ on the immune system}

In the last decade, immune system activation and inflammation have become widely recognized as an important underlying mechanism in the pathogenesis of hypertension. Estrogen is a known immunomodulator and is often considered to be anti-inflammatory, ${ }^{68,69}$ which would be considered as a mechanism protective against hypertension. However, estrogens can also promote B-cell activation, leading to increased antibody (humoral)-mediated immunity. ${ }^{70-72}$ This effect of estrogen in promoting humoral immunity is particularly relevant to hypertension for two major reasons. First, an increasing number of studies show that hypertension in humans and experimental models is associated with increased circulating autoantibodies ${ }^{73-75}$ consistent with systemic autoimmune diseases. Second, autoimmune diseases that predominantly affect women (like SLE) are associated with a markedly increased risk for developing hypertension and cardiovascular disease. Therefore, the complex regulation of cardiovascular risk factors by estrogens may result from a balance between anti-inflammatory and prohumoral immune system activation by estrogens. The impact of estrogens on immune system function represents a potentially robust area of research that could help to explain the impact of estrogens on hypertension and cardiovascular risk.

\section{Hormone therapy Hormone therapy and cardiovascular disease}

The vast evidence from both clinical and experimental studies showing that estrogen is protective against cardiovascular disease and hypertension leads many to believe that hormone therapy, ie, supplementing estrogen in postmenopausal women would be beneficial in preventing the disease following the natural loss of ovarian hormones associated with aging. However, much to everyone's surprise and disappointment, large-scale clinical trials, including the WHI and HERS-I and HERS-II, showed adverse outcomes of such therapies on cardiovascular risk and events. ${ }^{15,76,77}$ While many aspects of these trials remain controversial, the most likely explanation for the lack of anticipated protective effects is the age of the postmenopausal women who participated in the trials, the dosage and formulation of the hormones used, and the duration of therapy. One of the initial thoughts after the trials of combined conjugated equine estrogen (CEE)/medroxyprogesterone acetate therapy was that perhaps the protective effects of estrogen had been masked by progestin, prompting continuation of the CEE only arm of the WHI trial. This trial showed that $\mathrm{CEE}$ increased the risk of stroke, decreased the risk of hip fracture, and had no effect on coronary heart disease in postmenopausal women with prior hysterectomy over an average of 6.8 years. ${ }^{78}$ As a result, the trial was stopped early because the combined risk of stroke and coronary heart disease outweighed the benefits of a reduced risk of hip fracture. Recently, the report from the WHI extended post intervention follow-up of combined CEE/medroxyprogesterone acetate versus CEE alone trials concluded that hormone therapy should not be used for chronic disease prevention, although it is appropriate for management of symptoms in some women. ${ }^{79}$ However, the report did indicate that the risks and benefits were more balanced with CEE alone, especially for coronary heart disease, suggesting that there may still be some benefit to postmenopausal women, at least for coronary heart disease. ${ }^{79}$ Further supporting the notion that there may be a benefit from hormone therapy are the findings from this very same trial, in which younger women (aged 50-59 years) had more favorable results for all-cause mortality and myocardial infarction in the CEE only arm. ${ }^{79}$ These observations suggest that if hormone therapy is beneficial, that it is more efficacious in younger premenopausal women. Focusing on the effects of hormone therapy solely on cardiovascular disease, KEEPS (the Kronos Early Estrogen Prevention Study) was designed as a randomized, prospective, placebo-controlled trial to look specifically at the effects of oral CEE versus transdermal $17 \beta$-estradiol with or without progestin on atherosclerosis and coronary calcification in women within 3 years of menopause. ${ }^{80}$ The outcomes of this trial are expected to shed light on the potential benefits of single versus combined therapy on cardiovascular disease in postmenopausal women.

Given some of the adverse effects of the use of estrogens on the risk of breast cancer in particular, some studies have shifted their focus to selective estrogen receptor modulators, which bind to estrogen receptors to induce a functional profile distinct from that of estrogens. The multicenter, randomized, double-blind, placebo-controlled RUTH (Raloxifene Use for The Heart) trial was designed to evaluate the effect of raloxifene on the incidence of coronary events in postmenopausal women with documented cardiovascular disease or risk factors for the disease. The study concluded that the incidence of coronary events in women $<60$ years of age was significantly lower in those assigned raloxifene than in the placebo group; ${ }^{81}$ however, no difference was found between treatment groups in the incidence of coronary events in women $\geq 60$ and $<70$ or $\geq 70$ years of age ${ }^{81}$ The multicenter, international PEARL (Postmenopausal Evaluation And Risk 
reduction with Lasofoxifene) study, conducted in women aged 59-80 years mainly to examine the effects on osteoporosis, reported that women assigned to the higher but not lower dose of lasofoxifene experienced a reduction in the absolute incidence of major cardiovascular events. ${ }^{82}$ While these observations indicate that selective estrogen receptor modulators may have some potential benefit on cardiovascular disease, especially in younger women, it should be noted that these studies were not powered for clinical cardiovascular outcomes. Thus, the use of selective estrogen receptor modulators should be limited to treatment of perimenopausal symptoms and not primary prevention of cardiovascular disease.

\section{Hormone therapy in women with chronic disease}

Due to the fact that the vast majority of large clinical studies of the use of hormone therapy in women excluded subjects with chronic diseases such as diabetes and SLE, little is known about the potential benefit (or detriment) of hormone therapy on cardiovascular disease in these women. In a large, randomized, double-blind, placebo-controlled trial conducted in postmenopausal women with coronary heart disease, treatment with CEE along with medroxyprogesterone reduced the incidence of diabetes over 4 years. ${ }^{83}$ Similar beneficial effects were observed in postmenopausal women with type 2 diabetes, in whom treatment with CEE alone or CEE with medroxyprogesterone improved cardiovascular risk, including achieving better glycemic control, lipid metabolism, and decreased carotid wall thickness and atherosclerosis. ${ }^{84,85}$ However, conclusions regarding the potential benefit of hormone therapy for cardiovascular disease in patients with diabetes cannot be made based on the very few studies performed to date.

The LUMINA (LUpus in MInorities NAture versus nurture) study in a multiethnic US cohort showed that use of hormone therapy by postmenopausal women with SLE was not associated with vascular arterial events. ${ }^{86}$ Hochman et al examined the effects of hormone therapy and risk of cardiovascular disease in postmenopausal women with SLE. ${ }^{87}$ In their study, the incidence of coronary artery disease was similar between hormone therapy users and nonusers, ie, $11.4 \%$ (13 of 114 ) versus $13.7 \%$ (31 of 227), respectively, suggesting that hormone therapy does not predispose to coronary artery disease in postmenopausal women with SLE. While these observations seem to indicate that hormone therapy may be used safely for the treatment of menopausal symptoms in women with SLE, most of these studies have been conducted in small cohorts and have not truly and directly examined the effects of hormone therapy on cardiovascular risk. Thus, further studies are needed to determine the safety and potential beneficial effects of hormone therapy on cardiovascular disease in women with SLE.

\section{Hormone therapy and hypertension}

Data on the effect of hormone therapy on blood pressure also remains controversial. The PEPI (Postmenopausal Estrogen/Progestin Interventions) trial found no change in blood pressure following treatment with either estrogen alone or combined estrogen/progestin therapy. ${ }^{88}$ In contrast, in the WHI trial, women treated with a combined CEE/ progestin therapy had a higher prevalence of hypertension and a modest increase in blood pressure levels from baseline compared with placebo-treated women, even after adjusting for cardiovascular risk factors. ${ }^{89} \mathrm{~A}$ similar increase in blood pressure was observed in the CEE alone arm as well. While the current data suggest that hormone therapy should not be used for the treatment of hypertension per se, use of hormone therapy may be continued in hypertensive women for the treatment of severe symptoms of menopause if the benefits outweigh the risks.

\section{Conclusion}

Blood pressure levels and the prevalence of hypertension are generally lower in premenopausal women compared with age-matched men. However, this relationship no longer exists following menopause, suggesting an association between blood pressure regulation and changes in ovarian hormone levels. While experimental studies have shown that $17 \beta$-estradiol plays an important role in blood pressure control, use of hormone therapy to manage the risk and prevent development of hypertension and cardiovascular disease in women remains controversial.

\section{Disclosure}

The authors report no conflicts of interest in this work.

\section{References}

1. Wiinberg N, Hoegholm A, Christensen HR, et al. 24-h ambulatory blood pressure in 352 normal Danish subjects, related to age and gender. Am J Hypertens. 1995;8(10 Pt 1):978-986.

2. Stamler J, Stamler R, Riedlinger WF, Algera G, Roberts RH. Hypertension screening of 1 million Americans. Community Hypertension Evaluation Clinic (CHEC) program, 1973 through 1975. JAMA. 1976;235(21): 2299-2306.

3. Cheng S, Xanthakis V, Sullivan LM, Vasan RS. Blood pressure tracking over the adult life course: patterns and correlates in the Framingham heart study. Hypertension. 2012;60(6):1393-1399.

4. Rowland M, Roberts J. Blood pressure levels and hypertension in persons ages 6-74 years: United States, 1976-1980. Adv Data. 1982;84:1-11. 
5. Jackson LV, Thalange NK, Cole TJ. Blood pressure centiles for Great Britain. Arch Dis Child. 2007;92(4):298-303.

6. Muntner P, He J, Cutler JA, Wildman RP, Whelton PK. Trends in blood pressure among children and adolescents. JAMA. 2004;291(17): 2107-2113.

7. Dubey RK, Oparil S, Imthurn B, Jackson EK. Sex hormones and hypertension. Cardiovasc Res. 2002;53(3):688-708.

8. Meyer MR, Haas E, Barton M. Gender differences of cardiovascular disease: new perspectives for estrogen receptor signaling. Hypertension 2006;47(6):1019-1026.

9. Barton M, Meyer MR. Postmenopausal hypertension: mechanisms and therapy. Hypertension. 2009;54(1):11-18.

10. Taddei S. Blood pressure through aging and menopause. Climacteric. 2009;12 Suppl 1:36-40.

11. Staessen J, Bulpitt CJ, Fagard R, Lijnen P, Amery A. The influence of menopause on blood pressure. J Hum Hypertens. 1989;3(6):427-433.

12. Adams MR, Register TC, Golden DL, Wagner JD, Williams JK. Medroxyprogesterone acetate antagonizes inhibitory effects of conjugated equine estrogens on coronary artery atherosclerosis. Arterioscler Thromb Vasc Biol. 1997;17(1):217-221.

13. Rosano GM, Fini M. Comparative cardiovascular effects of different progestins in menopause. Int J Fertil Womens Med. 2001;46(5):248-256.

14. Rossouw JE, Anderson GL, Prentice RL, et al. Risks and benefits of estrogen plus progestin in healthy postmenopausal women: principal results from the Women's Health Initiative randomized controlled trial. JAMA. 2002;288(3):321-333.

15. Grady D, Herrington D, Bittner V, et al. Cardiovascular disease outcomes during 6.8 years of hormone therapy: Heart and Estrogen/progestin Replacement Study follow-up (HERS II). JAMA. 2002;288(1):49-57.

16. Yanes LL, Sartori-Valinotti JC, Iliescu R, et al. Testosterone-dependent hypertension and upregulation of intrarenal angiotensinogen in Dahl saltsensitive rats. Am J Physiol Renal Physiol. 2009;296(4):F771-F779.

17. Reckelhoff JF. Gender differences in the regulation of blood pressure Hypertension. 2001;37(5):1199-1208.

18. Reckelhoff JF, Zhang H, Srivastava K. Gender differences in development of hypertension in spontaneously hypertensive rats: role of the renin-angiotensin system. Hypertension. 2000;35(1 Pt 2):480-483.

19. Liu PY, Death AK, Handelsman DJ. Androgens and cardiovascular disease. Endocr Rev. 2003;24(3):313-340.

20. Yanes LL, Romero DG, Moulana M, et al. Cardiovascular-renal and metabolic characterization of a rat model of polycystic ovary syndrome. Gend Med. 2011;8(2):103-115.

21. Cutler JA, Sorlie PD, Wolz M, Thom T, Fields LE, Roccella EJ. Trends in hypertension prevalence, awareness, treatment, and control rates in United States adults between 1988-1994 and 1999-2004. Hypertension. 2008;52(5):818-827.

22. [No authors listed]. Blood pressure studies in 14 communities. A twostage screen for hypertension. JAMA. 1977;237(22):2385-2391

23. Zanchetti A, Facchetti R, Cesana GC, Modena MG, Pirrelli A, Sega R. Menopause-related blood pressure increase and its relationship to age and body mass index: the SIMONA epidemiological study. J Hypertens. 2005;23(12):2269-2276.

24. Pechere-Bertschi A, Burnier M. Female sex hormones, salt, and blood pressure regulation. Am J Hypertens. 2004;17(10):994-1001.

25. Kharazmi E, Fallah M, Luoto R. Cardiovascular diseases attributable to hysterectomy: a population-based study. Acta Obstet Gynecol Scand. 2007;86(12):1476-1483.

26. Schulman IH, Aranda P, Raij L, Veronesi M, Aranda FJ, Martin R. Surgical menopause increases salt sensitivity of blood pressure. Hypertension. 2006;47(6):1168-1174.

27. Salonia A, Lanzi R, Scavini M, et al. Sexual function and endocrine profile in fertile women with type 1 diabetes. Diabetes Care. 2006;29(2): 312-316.

28. Lamon-Fava S, Barnett JB, Woods MN, et al. Differences in serum sex hormone and plasma lipid levels in Caucasian and African-American premenopausal women. $J$ Clin Endocrinol Metab. 2005;90(8): 4516-4520.
29. Stamataki KE, Spina J, Rangou DB, Chlouverakis CS, Piaditis GP. Ovarian function in women with non-insulin dependent diabetes mellitus. Clin Endocrinol (Oxf). 1996;45(5):615-621.

30. Barrett-Connor E, Giardina EG, Gitt AK, Gudat U, Steinberg HO, Tschoepe D. Women and heart disease: the role of diabetes and hyperglycemia. Arch Intern Med. 2004;164(9):934-942.

31. Snell-Bergeon JK, Nadeau K. Cardiovascular disease risk in young people with type 1 diabetes. J Cardiovasc Transl Res. 2012;5(4):446-462.

32. Ding EL, Song Y, Malik VS, Liu S. Sex differences of endogenous sex hormones and risk of type 2 diabetes: a systematic review and metaanalysis. JAMA. 2006;295(11):1288-1299.

33. Stock EO, Redberg R. Cardiovascular disease in women. Curr Probl Cardiol. 2012;37(11):450-526.

34. Kannel WB. Blood pressure as a cardiovascular risk factor: prevention and treatment. JAMA. 1996;275(20):1571-1576.

35. Hosseinpoor AR, Harper S, Lee JH, Lynch J, Mathers C, Abou-Zahr C. International shortfall inequality in life expectancy in women and in men, 1950-2010. Bull World Health Organ. 2012;90(8):588-594.

36. Ford ES, Capewell S. Coronary heart disease mortality among young adults in the US from 1980 through 2002: concealed leveling of mortality rates. J Am Coll Cardiol. 2007;50(22):2128-2132.

37. Regitz-Zagrosek V, Dworatzek E, Kintscher U, Dragun D. Sex and sex hormone-dependent cardiovascular stress responses. Hypertension. 2013;61(2):270-277.

38. Melloni C, Berger JS, Wang TY, et al. Representation of women in randomized clinical trials of cardiovascular disease prevention. Circ Cardiovasc Qual Outcomes. 2010;3(2):135-142.

39. Worrall-Carter L, Ski C, Scruth E, Campbell M, Page K. Systematic review of cardiovascular disease in women: assessing the risk. Nurs Health Sci. 2011;13(4):529-535.

40. Khot UN, Khot MB, Bajzer CT, et al. Prevalence of conventional risk factors in patients with coronary heart disease. JAMA. 2003;290(7):898-904.

41. Stamler J, Stamler R, Neaton JD. Blood pressure, systolic and diastolic, and cardiovascular risks. US population data. Arch Intern Med. 1993;153(5):598-615.

42. Vasan RS, Larson MG, Leip EP, et al. Impact of high-normal blood pressure on the risk of cardiovascular disease. NEngl J Med. 2001;345(18): 1291-1297.

43. Stamler J, Dyer AR, Shekelle RB, Neaton J, Stamler R. Relationship of baseline major risk factors to coronary and all-cause mortality, and to longevity: findings from long-term follow-up of Chicago cohorts. Cardiology. 1993;82(2-3):191-222.

44. Yusuf S, Hawken S, Ounpuu S, et al. Effect of potentially modifiable risk factors associated with myocardial infarction in 52 countries (the INTERHEART study): case-control study. Lancet. 2004;364(9438): 937-952.

45. Manzi S, Meilahn EN, Rairie JE, et al. Age-specific incidence rates of myocardial infarction and angina in women with systemic lupus erythematosus: comparison with the Framingham Study. Am J Epidemiol. 1997;145(5):408-415.

46. Sabio JM, Vargas-Hitos JA, Navarrete-Navarrete N, et al. Prevalence of and factors associated with hypertension in young and old women with systemic lupus erythematosus. J Rheumatol. 2011;38(6):1026-1032.

47. Petri M. Detection of coronary artery disease and the role of traditional risk factors in the Hopkins Lupus Cohort. Lupus. 2000;9(3):170-175.

48. Nickenig G, Baumer AT, Grohe C, et al. Estrogen modulates AT1 receptor gene expression in vitro and in vivo. Circulation. 1998;97(22): 2197-2201.

49. Brosnihan KB, Li P, Ganten D, Ferrario CM. Estrogen protects transgenic hypertensive rats by shifting the vasoconstrictor-vasodilator balance of RAS. Am J Physiol. 1997;273(6 Pt 2):R1908-R1915.

50. Ergul A, Shoemaker K, Puett D, Tackett RL. Gender differences in the expression of endothelin receptors in human saphenous veins in vitro. J Pharmacol Exp Ther. 1998;285(2):511-517.

51. Polderman KH, Stehouwer CD, van Kamp GJ, Dekker GA, Verheugt FW, Gooren LJ. Influence of sex hormones on plasma endothelin levels. Ann Intern Med. 1993;118(6):429-432. 
52. Ylikorkala O, Orpana A, Puolakka J, Pyorala T, Viinikka L. Postmenopausal hormonal replacement decreases plasma levels of endothelin-1. J Clin Endocrinol Metab. 1995;80(11):3384-3387.

53. David FL, Carvalho MH, Cobra AL, et al. Ovarian hormones modulate endothelin-1 vascular reactivity and mRNA expression in DOCA-salt hypertensive rats. Hypertension. 2001;38(3 Pt 2):692-696.

54. Inarrea P, Casanova A, Alava MA, Iturralde M, Cadenas E. Melatonin and steroid hormones activate intermembrane $\mathrm{Cu}, \mathrm{Zn}$-superoxide dismutase by means of mitochondrial cytochrome P450. Free Radic Biol Med. 2011;50(11):1575-1581.

55. Dantas AP, Tostes RC, Fortes ZB, Costa SG, Nigro D, Carvalho MH. In vivo evidence for antioxidant potential of estrogen in microvessels of female spontaneously hypertensive rats. Hypertension. 2002; 39(2 Pt 2):405-411.

56. Guyton AC, Coleman TG, Cowley AV Jr, Scheel KW, Manning RD Jr, Norman RA Jr. Arterial pressure regulation. Overriding dominance of the kidneys in long-term regulation and in hypertension. Am J Med. 1972;52(5):584-594.

57. Neugarten J. Gender and the progression of renal disease. J Am Soc Nephrol. 2002;13(11):2807-2809.

58. Silbiger SR, Neugarten J. The role of gender in the progression of renal disease. Adv Ren Replace Ther. 2003;10(1):3-14.

59. Maric C, Sandberg K, Hinojosa-Laborde C. Glomerulosclerosis and tubulointerstitial fibrosis are attenuated with 17beta-estradiol in the aging Dahl salt-sensitive rat. J Am Soc Nephrol. 2004;15(6):1546-1556.

60. Elliot SJ, Karl M, Berho M, et al. Estrogen deficiency accelerates progression of glomerulosclerosis in susceptible mice. Am J Pathol. 2003;162(5):1441-1448.

61. Hinojosa-Laborde C, Craig T, Zheng W, Ji H, Haywood JR, Sandberg K. Ovariectomy augments hypertension in aging female Dahl salt-sensitive rats. Hypertension. 2004;44(4):405-409.

62. Cohen JA, Lindsey SH, Pirro NT, Brosnihan KB, Gallagher PE, Chappell MC. Influence of estrogen depletion and salt loading on renal angiotensinogen expression in the mRen(2). Lewis strain. Am J Physiol Renal Physiol. 2010;299(1):F35-F42.

63. Mankhey R, Wells CC, Bhatti F, Maric C. 17-beta estradiol supplementation reduces tubulointerstitial fibrosis by increasing MMP activity in the diabetic kidney. Am J Physiol Reg Integr Comp Physiol. 2006;292:R769-R777.

64. Negulescu O, Bognar I, Lei J, Devarajan P, Silbiger S, Neugarten J. Estradiol reverses TGF-beta1-induced mesangial cell apoptosis by a casein kinase 2-dependent mechanism. Kidney Int. 2002;62(6): 1989-1998.

65. Gallagher PE, Li P, Lenhart JR, Chappell MC, Brosnihan KB. Estrogen regulation of angiotensin-converting enzyme mRNA. Hypertension. 1999;33(1 Pt 2):323-328.

66. Morey AK, Razandi M, Pedram A, Hu RM, Prins BA, Levin ER. Oestrogen and progesterone inhibit the stimulated production of endothelin-1. Biochem J. 1998;330 Pt 3:1097-1105.

67. Xiao S, Gillespie DG, Baylis C, Jackson EK, Dubey RK. Effects of estradiol and its metabolites on glomerular endothelial nitric oxide synthesis and mesangial cell growth. Hypertension. 2001;37(2 Part 2): 645-650.

68. Verthelyi D. Sex hormones as immunomodulators in health and disease. Int Immunopharmacol. 2001;1(6):983-993.

69. Lang TJ. Estrogen as an immunomodulator. Clin Immunol. 2004;113(3): 224-230.

70. Salem ML. Estrogen, a double-edged sword: modulation of TH1and TH2-mediated inflammations by differential regulation of TH1/ TH2 cytokine production. Curr Drug Targets Inflamm Allergy. 2004;3(1):97-104.

71. Verthelyi DI, Ahmed SA. Estrogen increases the number of plasma cells and enhances their autoantibody production in nonautoimmune C57BL/6 mice. Cell Immunol. 1998;189(2):125-134.
72. Kanda N, Tamaki K. Estrogen enhances immunoglobulin production by human PBMCs. J Allergy Clin Immunol. 1999;103(2 Pt 1): 282-288.

73. Kristensen BO, Andersen PL, Wiik A. Autoantibodies and vascular events in essential hypertension: a five-year longitudinal study. J Hypertens. 1984;2(1):19-24.

74. Ofosu-Appiah W, Sfeir G, Kennell A, Richard T. Characterization of arterial antigens using arterial antigen-reactive $\mathrm{T}$ cell clones from spontaneously hypertensive rats. Am J Hypertens. 1997;10(5 Pt 1): $535-540$.

75. Dzielak DJ. Immune mechanisms in experimental and essential hypertension. Am J Physiol. 1991;260(3 Pt 2):R459-R467.

76. Manson JE, Hsia J, Johnson KC, et al. Estrogen plus progestin and the risk of coronary heart disease. $N$ Engl J Med. 2003;349(6):523-534.

77. Hulley S, Grady D, Bush T, et al. Randomized trial of estrogen plus progestin for secondary prevention of coronary heart disease in postmenopausal women. Heart and Estrogen/progestin Replacement Study (HERS) Research Group. JAMA. 1998;280(7):605-613.

78. Anderson GL, Limacher M, Assaf AR, et al. Effects of conjugated equine estrogen in postmenopausal women with hysterectomy: the Women's Health Initiative randomized controlled trial. JAMA. 2004;291(14):1701-1712.

79. Manson JE, Chlebowski RT, Stefanick ML, et al. Menopausal hormone therapy and health outcomes during the intervention and extended poststopping phases of the Women's Health Initiative randomized trials. JAMA. 2013;310(13):1353-1368

80. Miller VM, Black DM, Brinton EA, et al. Using basic science to design a clinical trial: baseline characteristics of women enrolled in the Kronos Early Estrogen Prevention Study (KEEPS). J Cardiovasc Transl Res. 2009;2(3):228-239.

81. Collins P, Mosca L, Geiger MJ, et al. Effects of the selective estrogen receptor modulator raloxifene on coronary outcomes in the raloxifene use for the heart trial: results of subgroup analyses by age and other factors. Circulation. 2009;119(7):922-930.

82. Cummings SR, Ensrud K, Delmas PD, et al. Lasofoxifene in postmenopausal women with osteoporosis. $N$ Engl J Med. 2010;362(8): 686-696.

83. Kanaya AM, Herrington D, Vittinghoff E, et al. Glycemic effects of postmenopausal hormone therapy: the Heart and Estrogen/progestin Replacement Study. A randomized, double-blind, placebo-controlled trial. Ann Intern Med. 2003;138(1):1-9.

84. Friday KE, Dong C, Fontenot RU. Conjugated equine estrogen improves glycemic control and blood lipoproteins in postmenopausal women with type 2 diabetes. J Clin Endocrinol Metab. 2001;86(1):48-52.

85. Ferrara A, Karter AJ, Ackerson LM, Liu JY, Selby JV. Hormone replacement therapy is associated with better glycemic control in women with type 2 diabetes: the Northern California Kaiser Permanente Diabetes Registry. Diabetes Care. 2001;24(7):1144-1150.

86. Fernandez M, Calvo-Alen J, Bertoli AM, et al. Systemic lupus erythematosus in a multiethnic US cohort (LUMINA L II): relationship between vascular events and the use of hormone replacement therapy in postmenopausal women. J Clin Rheumatol. 2007;13(5):261-265.

87. Hochman J, Urowitz MB, Ibanez D, Gladman DD. Hormone replacement therapy in women with systemic lupus erythematosus and risk of cardiovascular disease. Lupus. 2009;18(4):313-317.

88. [No authors listed]. Effects of estrogen or estrogen/progestin regimens on heart disease risk factors in postmenopausal women. The Postmenopausal Estrogen/Progestin Interventions (PEPI) Trial. The Writing Group for the PEPI Trial. JAMA. 1995;273(3):199-208.

89. Wassertheil-Smoller S, Anderson G, Psaty BM, et al. Hypertension and its treatment in postmenopausal women: baseline data from the Women's Health Initiative. Hypertension. 2000;36(5):780-789. 
International Journal of Women's Health

Dovepress

\section{Publish your work in this journal}

The International Journal of Women's Health is an international, peerreviewed open-access journal publishing original research, reports, editorials, reviews and commentaries on all aspects of women's healthcare including gynecology, obstetrics, and breast cancer. The manuscript management system is completely online and includes Visit http://www.dovepress.com/testimonials.php to read real quotes from published authors.

Submit your manuscript here: http://www.dovepress.com/international-journal-of-womens-health-journal 